\title{
Prevalence of Gender Nonconformity in Flanders, Belgium
}

Eva Van Caenegem, ${ }^{1 *}$ Katrien Wierckx, ${ }^{1 *}$ Els Elaut, ${ }^{2,5}$ Ann Buysse, ${ }^{3}$ Alexis Dewaele, ${ }^{3}$ Filip Van Nieuwerburgh, ${ }^{4}$ Griet De Cuypere, ${ }^{2}$ and Guy T'Sjoen ${ }^{1,2}$

${ }^{1}$ Department of Endocrinology, Ghent University Hospital, Ghent, Belgium

${ }^{2}$ Center for Sexology and Gender Problems, Ghent University Hospital, Ghent, Belgium

${ }^{3}$ Department for Experimental, Clinical and Health Psychology, Ghent University, Ghent, Belgium

${ }^{4}$ Laboratory of Pharmaceutical Biotechnology, Ghent University, Ghent, Belgium

${ }^{5}$ To whom correspondence should be addressed at Center for Sexology and Gender Problems (1B2), Ghent University Hospital, De Pintelaan 185, 9000 Ghent, Belgium; e-mail: els.elaut@ugent.be

* These authors contributed equally. 


\begin{abstract}
Gender nonconformity refers to the extent to which a person's gender identity, gender role and/or gender expression differs from the cultural norms prescribed for people of a particular sex, within a certain society and era. Most data on gender nonconformity focus on the prevalence of gender dysphoria (which also includes a distress factor) or on the number of legal sex changes. However, not every gender nonconforming individual experiences distress or applies for treatment. Population-based research on the broad spectrum of gender nonconformity is scarce and more information on the variance outside the gender binary is needed. This study aimed to examine the prevalence of gender incongruence (identifying stronger with the other sex than with the sex assigned at birth) and gender ambivalence (identifying equally with the other sex as with the sex assigned at birth) based on two population-based surveys, one of 1,832 Flemish persons and one of 2,472 sexual minority individuals in Flanders. In the general population, gender ambivalence was present in $2.2 \%$ of male and $1.9 \%$ of female participants, whereas gender incongruence was found in $0.7 \%$ of men and $0.6 \%$ of women. In sexual minority individuals, the prevalence of gender ambivalence and gender incongruence was $1.8 \%$ and $0.9 \%$ in men and $4.1 \%$ and $2.1 \%$ in women, respectively. With a current Flemish population of about 6 million, our results indicate a total of between 17,150 and 17,665 gender incongruent men and between 14,473 and 15,221 gender incongruent women in Flanders.
\end{abstract}

Keywords: Gender identity; gender nonconformity, SEXPERT; Belgium 


\section{INTRODUCTION}

Gender nonconformity refers to the extent to which a person's gender identity, role or expression differs from the cultural norms prescribed for people of a particular sex, within a certain society and era. Gender dysphoria refers to the discomfort or distress that is caused by this incongruence between a person's gender identity and that person's sex assigned at birth (as well as the associated gender role and/or primary and secondary sex characteristics). The World Professional Association for Transgender Health stresses that only certain gender nonconforming people experience gender dysphoria at some point in their lives (Coleman et al., 2011). Although gender dysphoria is the most well known form, gender nonconformity can be observed within a wide range of diagnostic categories (DSM-5, 302.85; ICD-10, F64.0).

However, the definition of gender dysphoria in current research has not been uniform: prevalence numbers were based on the number of legal sex changes as noted in a national register (Veale, 2008), the start of cross-sex hormonal therapy (Bakker, van Kesteren, Gooren, \& Bezemer, 1993; Eklund, Gooren, \& Bezemer, 1988; Van Kesteren, Gooren, \& Megens, 1996), the number of applicants for sex reassignment surgeries (SRS) (Olsson \& Möller, 2003), the number of SRSs performed by different surgical centers (De Cuypere et al., 2007), or the attendance at a gender clinic (Baba et al., 2011). For example, the Belgian prevalence was based on the number of SRSs performed in Belgium, and was estimated at 1: 12,900 for male-to-female and 1:33,800 for female-to-male transsexual persons (De Cuypere et al., 2007). These interpretations of gender dysphoria imply an important selection bias as only those who seek and/or have access to medical and/or surgical treatment are counted. Indeed, a primary care study revealed that $40 \%$ of people defined as having a gender identity problem who consulted a general practitioner had not received hormonal therapy or SRS (Wilson, Sharp, \& Carr, 1999). This suggests that many gender incongruent persons are probably not 
attending a secondary care service or gender clinic. Some persons may be reluctant to seek health care and treatment due to financial restraints, shame, or fear of potential social exclusion, such as losing one's family, job, friends or partner (De Cuypere et al., 2007; Kuyper \& Wijsen, 2014; Zucker \& Lawrence, 2009) whereas others may simply not desire hormonal treatment, SRS, or change of official documents. Our knowledge concerning this broader spectrum of gender nonconformity is currently scant (Conron, Scott, Stowel, \& Landers, 2012; Kuyper \& Wijsen, 2014). However, this information is needed to inform society on gender diversity beyond the gender binary and to address the potential needs of this group.

In a telephone health survey in the United States, $0.5 \%$ of the participants identified themselves as transgender (Conron, Scott, Stowell, \& Landers, 2012) and in the Netherlands, Kuyper and Wijsen (2014) asked participants if they felt psychologically male and/or female in an Internet-based population survey. Ambivalent gender identity (identifying equally with the other sex as with the sex assigned at birth) was reported in $4.6 \%$ of men and $3.2 \%$ of women, and incongruent gender identity (identifying stronger with the other sex than with the sex assigned at birth) in $1.1 \%$ and $0.8 \%$. The study of Kuyper and Wijsen (2014) was however no representative population survey and had a low response rate (20.9\%), and, hence, could be subject to selection bias as acknowledged by the authors.

Population-based research is therefore required to provide an estimation of the actual prevalence of gender nonconformity. The first aim of this study was to investigate the prevalence of gender nonconformity in the general population in Flanders (Belgium). In particular, we measured gender incongruence (identifying stronger with the other sex than with the sex assigned at birth, GI) and gender ambivalence (identifying equally with the other sex as with the sex assigned at birth, GA). As the Netherlands and Belgium are neighboring countries sharing not only a language but also a common cultural and political history (De 
Cuypere, Jannes \& Rubens, 1995, p.183), a comparison of the prevalence observed in the Dutch survey of Kuyper and Wijsen (2014) with the Flemish data is warranted.

Although it has not been proven, it is held believed in many people, including health care professionals, that gender dysphoria is more frequent in lesbian, gay and bisexual (LGB) individuals. Therefore, the second aim of this study is to examine gender incongruence and ambivalence in sexual minority individuals.

\section{METHOD}

\section{Participants}

In order to comply with its first aim, this study used data from the survey "Sexual Health in Flanders" (Buysse et al., 2013), a large-scale representative survey on sexuality, sexual health, and relationships in Flanders (the northern, Flemish-speaking part of Belgium with about 6 million inhabitants). The survey contained extensive information on sexual health characteristics and demographic, biomedical, psychological, and sociocultural correlates. It aims to investigate sexual health in Flanders and seeks possible explanations using bio-medical, psychological, demographic and socio-cultural correlates. For this survey, participants aged between 14 and 80 years were randomly selected from the Belgian National Register. Data were collected between February 2011 and January 2012. The final database consisted of 1,832 participants (response rate: $40.0 \%$ of the eligible participants). In order to enhance the statistical power in each of the three pre-defined age categories, we used a stratified sample with one-third of the sample consisting of adolescents (aged 14 to 25), onethird of persons from the middle age group (aged 26 to 49), and one-third of persons from the oldest group (50 to 80 years old). Following Dillman's Total Design Method (Dillman, 1978, 2000), elaborate contact procedures were used to maximize the cooperation, the (item) response, and the quality of all survey measures. After data collection, the data were weighted 
by gender, age, and schooling level in order to make them representative of the population of Flanders aged $14-80$ years.

The data were gathered via face-to-face interviews in combination with computerassisted personal interviewing (CAPI) and computer-assisted self-interviewing (CASI). In particular, the sensitive information (i.e., a wide range of sexual health characteristics) was obtained in a CASI set-up, so that participants did not have to share private information about their sexual health with the interviewer. The items on gender identity and role were assessed by CAPI. The mean duration of an interview was 84 minutes and no token was provided. The details of the study design have been described elsewhere (Buysse et al., 2013).

The second study used data from the Internet-based survey "Click Out of the Bed Room," a large-scale survey on sexuality, sexual health, and relationships among sexual minority individuals in Flanders. The questionnaire was identical to one used in the first part of the study but significantly shorter to avoid participant drop out. The objective of this study was to examine the sexual health of sexual minority individuals in Flanders and, therefore, only contained questions on sexual health indicators. Only a few biomedical, psychological, demographic and sociocultural correlates were included. For this survey, it was important to recruit sexual minority individuals who did not identify themselves as gay, lesbian or bisexual. To this end, we set up a neutral as well as a LGB-oriented campaign. For the neutral campaign, 10,000 posters were disseminated across Flanders containing an image that did not specifically refer to being lesbian, gay or bisexual. The message on the poster presented the survey as related to sexual health in general. We dispersed banners, advertisements on the Internet, and press releases which also contained this neutral image and message. In addition, we set up a specific recruitment strategy to target sexual minority individuals. This strategy included broadcasting a request for participants through the following channels: specific locations such as LGB discotheques, LGB parties, and LGB events; advertisements in the 
written press; LGB-specific and non-LGB-specific associations and organizations; electronic mailings and the Internet (banners on LGB-specific websites). More details on the recruitment have been described elsewhere (Dewaele, Caen, \& Buysse, 2014).

Data were collected between September 2011 and March 2012, resulting in a final database of 3,702 participants between 13 and 86 years old. Out of the total number of participants, 35.4\% found our site through a social network site (mainly Facebook), 18.5\% through an electronic mailing, $15.3 \%$ through television, radio, a newspaper or a magazine, $10.6 \%$ through clicking on a banner on a website, $6.7 \%$ through their school or work, $3.7 \%$ through a gadget or flyer, $2.2 \%$ through an association or activity, 1.7\% through a poster, and $5.8 \%$ through other means.

Both studies were approved by a Medical Ethical Committee, and all participants gave consent for participation to the study. The general characteristics of the two populations are shown in Table 1.

\section{Measures}

Gender identity and expression were assessed as described by Schoonacker, Dumon, and Louckx (2009) by asking participants to score six items on a 5-point Likert scale $(1=$ totally disagree, 5 = totally agree): "I feel like a woman" (Item 1), "I feel like a man" (Item 2), "I look feminine" (Item 3), "I look masculine" (Item 4), "I wish to be more feminine" (Item 5), "I wish to be more masculine" (Item 6). Based on the first two items, the presence of gender ambivalence (yes/no) and gender incongruence (yes/no) was assessed similarly to previous research (Bockting, Benner, \& Coleman, 2009; Kuyper \& Wijsen, 2014). A person was considered to be gender ambivalent if the same answer was given for Item 1 and 2 (scores $1-1 ; 2-2 ; 3-3 ; 4-4$; and 5-5), whereas an incongruent gender identity was reflected in a higher score on the item of feeling like the opposite sex than on that of feeling like the sex assigned at birth (scores $1-2 ; 1-3 ; 1-4 ; 1-5 ; 2-3 ; 2-4 ; 2-5 ; 3-4 ; 3-5 ; 4-5$ ). 
The items on sociodemographic variables are described elsewhere (Buysse et al., 2013; Dewaele, Caen, \& Buysse, 2014).

In the sexual minority individual survey, sexual orientation was conceptualized as a three-dimensional construct measuring self-identification, sexual behavior, and sexual desire (Laumann, Gagnon, Michael, \& Michaels, 1994). These dimensions were used to acquire a broader definition of LGB, as it is important to include persons who display homosexual behavior but do not identify themselves as LGB (Mercer et al., 2007; van Kesteren, Hospers, \& Kok, 2007). First, sexual self-identification was assessed by means of the following question: "How would you identify yourself?" The answer had to be marked on a 5-point Likert scale (i.e., straight, more straight then gay/lesbian, bisexual, more gay/lesbian than straight, gay/lesbian), and an open-ended response category was added for participants who did not identify with any of these labels (referred to as "other"). Secondly, to measure sexual behavior, the participants were asked two questions: "Throughout your life, with how many people did you have sex?" (open-ended numeric answer category); and "Were these people men, women or both?” The latter question was to be scored on a 5-point Likert scale (from 1 $=$ only women to $5=$ only men). Finally, sexual desire was measured by asking participants to score the following questions on a 5-point Likert scale (from $1=$ only about or to women to $5=$ only about or to men): "Do you sexually fantasize about men, women or both?" and "Do you feel sexually attracted to men, women or both?" The participants could also answer these questions with "only about/to none." With the information from these four items, a dichotomous variable was created, categorizing participants as non-heterosexual (i.e., "0") or heterosexual (i.e., “1”). They were identified as non-heterosexual when they reported to identify as gay/lesbian, bisexual or more gay/lesbian than straight and/or when they reported to have at least as many same-sex sexual fantasies as opposite sex fantasies, and/or when they reported to feel at least as often attracted to the same-sex as to the opposite sex, and/or to have 
had at least as many same-sex sexual contacts as with the opposite sex (Dewaele, Caen, \& Buysse, 2014). This classification resulted in a total of 2,472 non-heterosexual persons to be included in our analyses; persons defined as heterosexual were excluded.

\section{Statistical Analysis}

Chi-square analysis was used to evaluate the differences in gender incongruence and gender ambivalence between men and women and to compare the prevalence with previous research (Kuyper \& Wijsen, 2014). All data were analyzed using SPSS software version 21 (SPSS Inc., Chicago, IL).

\section{RESULTS}

\section{Population-Based Study}

In Flemish men, $1.4 \%$ reported feeling like a woman and $2.4 \%$ did not feel like a man. Of all men, $2.3 \%$ desired to be more feminine whereas $48.8 \%$ did not want to be more masculine. When asked about their appearance, $1.1 \%$ of men thought that they looked feminine and $2.2 \%$ believed that they do not look masculine.

In Flemish women, $1.7 \%$ reported feeling like a man and $1.5 \%$ did not feel like a women. Of all women, $1.1 \%$ wanted to be more masculine while $95.6 \%$ did not wish to be more masculine. When asked about their appearance, $1.6 \%$ of women reported having a masculine look and $1.9 \%$ believed that they do not look feminine.

Gender ambivalence was found in $2.2 \%$ of men and $1.9 \%$ of women whereas the prevalence of gender incongruence was $0.7 \%$ and $0.6 \%$, respectively (Table 3). Prevalence rates of gender ambivalence and incongruence did not significantly differ between men and women $\left(\chi^{2}=1.28\right)$. Furthermore, not all gender-ambivalent or gender-incongruent persons wished to be more like the opposite sex. A variation in appearance and desire to be more masculine or feminine was observed (Table 4).

\section{Sexual Minority Individual Survey}


In the LGB survey, the prevalence of gender incongruence was $0.9 \%$ in men and $2.1 \%$ in women (Table 5), while that of gender ambivalence was $1.8 \%$ and $4.1 \%$, respectively. Prevalence rates of gender ambivalence and incongruence were significantly different between men and women (GA: $\chi^{2}=10.95, p<.001$; GI: $\left.\chi^{2}=5.39, p=.02\right)$. When compared to the population-based survey, the prevalence of gender incongruence and ambivalence was found to be higher in LGB women $\left(\mathrm{GA}: \chi^{2}=6.84, p=.009\right.$; GI: $\left.\chi^{2}=6.60, p=.01\right)$, whereas no differences in prevalence rates were observed for GB men (GA: $\chi^{2}<1$; GI: $\left.\chi^{2}<1\right)$.

\section{Comparison with Previous Research}

A comparison of the current results with the findings of Kuyper and Wijsen (2014) is shown in Table 6 . In this study conducted in a neighboring country, the Netherlands, Kuyper and Wijsen asked participants if they felt psychologically male and/or female in an Internetbased population survey. The participants were asked to score two items on a 5-point Likertscale $(1=$ totally disagree, $5=$ totally agree $)$. By use of a random sample, the Dutch participants were recruited from a large Internet panel for online surveys, whose members received so-called "clix" for participating in online surveys which they could use to buy products on the Internet. During data gathering, representativeness for the Dutch population was checked, and recruitment was adapted in order to complete shortages or limit overrepresented population groups.

The observed percentages of gender incongruence in the Netherlands were comparable to those in our study. However, the prevalence of gender ambivalence in men was higher in the Dutch survey (Table 6).

\section{DISCUSSION}

This is the first study investigating the prevalence of gender nonconformity in the Flemish population and one of the few studies assessing gender nonconformity in a population-based survey. We found a prevalence of gender incongruence of $0.7 \%$ and $0.6 \%$ 
and of gender ambivalence of $2.2 \%$ and $1.9 \%$ in men and women, respectively. Extrapolated to the current number of Flemish inhabitants, gender ambivalence would concern between 54,256 and 55,162 men (95\% confidence interval) and between 47,020 and 47,865 women, and gender incongruence between 17,150 and 17,665 men and between 14,743 and 15,221 women. Two recent population surveys reported similar findings (Conron, Scott, Stowell, \& Landers, 2012; Kuyper \& Wijsen, 2014). Conron et al. explicitly asked 28,662 residents of Massachusetts if they would consider themselves to be transgender, and $0.5 \%$ of the participants identified themselves as transgender in a telephone health survey. In the Netherlands, Kuyper and Wijsen asked participants if they felt psychologically male and/or female in an Internet-based population survey. Ambivalent gender identity was reported in $4.6 \%$ of men and $3.2 \%$ of women, and incongruent gender identity in $1.1 \%$ and $0.8 \%$, respectively. This Dutch survey had a similar prevalence rate of gender incongruence but a higher prevalence of gender ambivalent men (significant in men, trend towards significance in women), compared to our results. Differences in methodology should be considered (a representative stratified sample randomly drawn from the National Register versus an Internet-based stratified sample) as well as differences in response rate (20.9\% versus $40.0 \%)$ and in the phrasing of the questions. Further, while views on and policies for people with gender dysphoria are highly similar in Belgium and The Netherlands today; it could be hypothesized that the higher gender ambivalence (especially in Dutch men) is related to more liberal norms and stronger social acceptance in the Dutch society.

The currently observed numbers are much higher than the prevalence of gender dysphoria in clinical settings. As mentioned before, the prevalence rate of transsexualism in Belgium was estimated at 1:12,900 for male-to-female and 1:33,800 for female-to-male trans persons (De Cuypere et al., 2007). Consistent with the broader definition of gender nonconformity, our findings confirm that prevalence rates based on the number of individuals 
seeking medical help underestimate the prevalence of gender nonconformity in the general adult population. In our sexual minority individual survey, we found a prevalence of gender incongruence of $0.9 \%$ and $2.1 \%$, and of gender ambivalence of $1.8 \%$ and $4.1 \%$ in men and women, respectively. The observed prevalence of gender incongruence and ambivalence was generally higher in women than in men in the sexual minority individual survey.

We also found that gender incongruent or gender ambivalent persons varied in their reported appearance and desire to be more masculine or feminine. Our results may thus support the hypothesis that gender-nonconforming people varied in (preferred) gender expression. Therefore, the prevalence rates of gender nonconformity were expected to be much higher than earlier figures which were based on the number of people who underwent SRS in Belgium (De Cuypere et al., 2007). Indeed, Kuyper and Wijsen (2014) observed that only a minority of gender-incongruent or gender-ambivalent persons were dissatisfied with their body and wished to undergo treatment. However, as we have not investigated the prevalence of dysphoria or desire for sex reassignment treatment in our current studies, we cannot confirm these findings.

The strengths of our study were, on the one hand, the use of a large representative population survey and, on the other hand, the use of identical questionnaires in a large sample of sexual minority individuals. However, our study was hampered by the differences in methodology between these two surveys, which also resulted in a different sociodemographic population. The comparison with the Dutch survey may be limited due to different design and smaller sample size of the current study. We also acknowledge that the response rate of $40 \%$ seems low though very similar response rates have been found in other European, populationbased surveys on sexual health and/or sexual behavior, such as a study in Finland (response rate of $46 \%$ ) or another conducted in Estonia and St. Petersburg (response rate of 41\%) (Gronow et al., 1997; Haavio-Mannila \& Kontula, 2001). As the sex classification is drawn 
from the national register, our results could be confounded by people with gender dysphoria who already underwent sex reassignment surgery and belonged legally to the other sex than their birth sex. However, medication use and medical history was included in the survey and we could not find any trace of cross-sex hormonal therapy or history of sex reassignment surgery. Further, sexual minority individuals are considered a hard-to-reach population. In addition, in national surveys, the numbers of men and women identified as being nonheterosexual are often too low to allow for a thorough statistical analysis. In order to acquire a sufficient number of sexual minority individuals, large population-based samples are required. Together with the costs and efforts that are typically associated with population-based representative surveys, especially in small communities like Flanders, this requirement makes it very hard to acquire adequate data (Dewaele, Caen, \& Buysse, 2014). Therefore, we believe that this study adds valuable information on the prevalence of gender ambivalence and gender incongruence in sexual minority individuals, despite the methodological shortcomings. Future studies should investigate these prevalence rates in larger representative population-based surveys to ensure sufficient power. Finally, information on experiencing gender dysphoric feelings and desiring treatment in gender-ambivalent and gender-incongruent persons were not included in our study. Future studies should take this into account.

\section{Acknowledgments}

The Sexpert study group consists of Ann Buysse (Ghent University: Department of experimental clinical and health psychology), Paul Enzlin (KU Leuven, Department of Development and Regeneration, Institute for Family and Sexuality Studies and UPC KU Leuven, Context-Center for couple, family and sex therapy), Guy T'Sjoen (Ghent University Hospital: Department of Endocrinology and Center for Sexology and Gender problems), John Lievens, Mieke Van Houtte, and Hans Vermeersch (Ghent University: Department of Sociology, research team cultural diversity: opportunities \& socialisation). The Sexpert study 
was funded by the Strategic Basic Research program of the Flemish Agency for Innovation by Science and Technology. 


\section{REFERENCES}

Baba, T., Endo, T., Ikeda, K., Shimizu, A., Honnma, H., Ikeda, H., ... Saito, T. (2011). Distinctive features of female-to-male transsexualism and prevalence of gender identity disorder in Japan. Journal of Sexual Medicine, 8, 1686-1693.

Bakker, A., van Kesteren, P. J., Gooren, L. J., \& Bezemer, P. D. (1993). The prevalence of transsexualism in The Netherlands. Acta Psychiatrica Scandinavica, 87, 237-238.

Belgian National Registry. Retrieved on April 26, 2013, from http://statbel.fgov.be/

Bockting, W., Benner, A., \& Coleman, E. (2009). Gay and bisexual identity development among female-to-male transsexuals in North America: Emergence of a transgender sexuality. Archives of Sexual Behavior, 38, 688-701.

Buysse, A., Caen, M., Dewaele, A., Enzlin, P., Lievens, J., T’Sjoen, G., ... Vermeersch, H. (2013). SEXPERT. Seksuele gezondheid in Vlaanderen [Sexual Health in Flanders]. Ghent, Belgium: Academia Press.

Bye, L., Gruskin, E., Greenwood, G., Albright, V., \& Krotki, K. (2005). California Lesbians, Gays, Bisexuals, and Transgender (LGBT) Tobacco Use Survey (2004). Sacramento, CA: California Department of Health Services.

Coleman, E., Bockting, W., Botzer, M., Cohen-Kettenis, P. T., De Cuypere, G., Feldman, J., ... Zucker, K. (2011). Standards of Care for the Health of Transsexual, Transgender and Gender Nonconforming People. $7^{\text {th }}$ edition. International Journal of Transgenderism, 13, 165-232.

Conron, K. J., Scott, G., Stowell, G. S., \& Landers, S. J. (2012). Transgender health in Massachusetts: Results from a household probability sample of adults. American Journal of Public Health, 102, 118-122. 
De Cuypere, G., Jannes, C., \& Rubens, R. (1995). Psychosocial functioning of transsexuals in Belgium. Acta Psychiatrica Scandinavica, 91, 180-184.

De Cuypere, G., Van Hemelrijck, M., Michel, A., Carael, B., Heylens, G., Rubens, R., Hoebeke, P., \& Monstrey, S. (2007). Prevalence and demography of transsexualism in Belgium. European Psychiatry, 22, 137-141.

Dewaele, A., Caen, M., \& Buysse, A. (2014). Comparing survey and sampling methods for reaching sexual minority individuals in Flanders. Journal of Official Statistics, 30, 251-275.

Eklund, P. L., Gooren, L. J., \& Bezemer, P. D. (1988). Prevalence of transsexualism in The Netherlands. Britisch Journal of Psychiatry, 152, 638-640.

Garrels, L., Kockott, G., Michael, N., Preuss, W., Renter, K., Schmidt, G., \& Windgassen, K. (2000). Sex ratio of transsexuals in Germany: The development over three decades. Acta Psychiatrica Scandinavica, 102, 445-448.

Gates, G. (2011). How many people are LGBT? Los Angeles: UCLA School of Law, Williams Institute. Retrieved $22^{\text {nd }}$ Feb 2013, from http://williamsinstitute.law.ucla.edu/wp-content/uploads/Gates-How-Many-People-

\section{LGBT-Apr-2011.pdf}

Gronow, J., Haavio-Mannila, E., Kivinen, M., Lonkila, M., \& Rotkirch, A. (1997). Cultural inertia and social change in Russia. Helsinki: University of Helsinki, Department of Sociology.

Haavio-Mannila, E., \& Kontula, O. (2001). Seksin Trendit Meillä ja Naapureissa. Helsinki: WSOY.

Kuyper, L., \& Wijsen C. (2014). Gender identities and gender dysphoria in the Netherlands. Archives of Sexual Behavior, 43, 377-385. 
Laumann, E., Gagnon, J. H., Michael, R. T., \& Michaels, S. (1994). The social organization of sexuality: Sexual practices in the United States. Chicago: University of Chicago Press.

Mercer, C. H., Bailey, J. V., Johnson, A. M., Erens, B., Wellings, K., Fenton, K. A., \& Copas, A. J. (2007). Women who report having sex with women: British national probability data on prevalence, sexual behaviors, and health outcomes. American Journal of Public Health, 97, 1126-1133.

Olsson, S. E., \& Moller, A. R. (2003). On the incidence and sex ratio of transsexualism in Sweden, 1972-2002. Archives of Sexual Behavior, 32, 381-386.

Reed, B., Rhodes, S., Schofield, P., \& Wylie, K. (2009). Gender variance in the UK: Prevalence, incidence, growth and geographic distribution. Retrieved at www.gires.org.uk/assets/Medpro-Assets/GenderVarianceUK-report.pdf

Schoonacker, M., Dumon, E., \& Louckx, F. (2009). WELEBI. Onderzoek naar het mentaal en sociaal welbevinden van lesbische en biseksuele meisjes [Study on the mental and social well-being of lesbian and bisexual girls]. Brussels, Belgium: Vrije Universiteit Brussel.

Van Kesteren, P. J., Gooren, L. J., \& Megens, J. A. (1996). An epidemiological and demographic study of transsexuals in The Netherlands. Archives of Sexual Behavior, $25,589-600$.

Van Kesteren, N. M. C., Hospers, H., \& Kok, G. (2007) Sexual risk behavior among HIV positive men who have sex with men: A literature review. Patient Education and Counseling, 65, 5-20.

Veale, J. F. (2008). Prevalence of transsexualism among New Zealand passport holders. Australian and New Zealand Journal of Psychiatry, 42, 887-889. 
Wilson, P., Sharp, C., \& Carr, S. (1999). The prevalence of gender dysphoria in Scotland: a primary care study. British Journal of General Practice, 49, 991-992.

Zucker, K. J., Bradley, S. J., Owen-Anderson, A., Kibblewhite, S. J., \& Cantor, J. M. (2008). Is gender identity disorder in adolescents coming out of the closet? [Letter to the editor] Journal of Sex \& Marital Therapy, 34, 287-290.

Zucker, K. J., \& Lawrence, A. A. (2009). Epidemiology of gender identity disorder: Recommendations for the Standards of Care of the World Professional Association for Transgender Health. International Journal of Transgenderism, 11, 8-18. 
Table 1 General characteristics of the study populations

\begin{tabular}{|c|c|c|}
\hline & $\begin{array}{l}\text { Population } \\
\text { survey } \\
(\mathrm{n}=1832)\end{array}$ & $\begin{array}{l}\text { Sexual minority } \\
\text { survey } \\
\quad(n=2472)\end{array}$ \\
\hline \multicolumn{3}{|l|}{ Gender } \\
\hline Women & 49.8 & 37.4 \\
\hline Men & 50.2 & 62.6 \\
\hline \multicolumn{3}{|l|}{ Age (years) } \\
\hline$\leq 29$ & 27.0 & 49.0 \\
\hline $30-49$ & 34.1 & 37.5 \\
\hline $50-80$ & 39.1 & 13.5 \\
\hline \multicolumn{3}{|l|}{ Education } \\
\hline School going & 11.6 & 27.8 \\
\hline None / Primary School & 18.2 & 1.4 \\
\hline Primary high School & 20.4 & 4.6 \\
\hline Secondary high School & 22.5 & 17.8 \\
\hline Bachelor/master & 27.0 & 48.3 \\
\hline \multicolumn{3}{|l|}{ Partner } \\
\hline Yes & 77.4 & 36.7 \\
\hline No & 22.6 & 63.3 \\
\hline \multicolumn{3}{|l|}{ Religion } \\
\hline No religion & 15 & \\
\hline Unbelieving & 8.4 & \\
\hline Catholic & 41.4 & \\
\hline Christian, but not Catholic & 17.3 & \\
\hline
\end{tabular}




\begin{tabular}{|c|c|}
\hline Islamic & 1.8 \\
\hline Jewish & 0.1 \\
\hline Buddhist & 0.3 \\
\hline Believe in something (not specified) & 8.4 \\
\hline Indifferent & 6.9 \\
\hline Other & 0.4 \\
\hline \multicolumn{2}{|l|}{ Nationality } \\
\hline Belgian & 96.9 \\
\hline Other & 3.1 \\
\hline \multicolumn{2}{|l|}{ Nationality father } \\
\hline Belgian & 94.1 \\
\hline Other & 5.9 \\
\hline \multicolumn{2}{|l|}{ Nationality mother } \\
\hline Belgian & 96.9 \\
\hline Other & 3.1 \\
\hline
\end{tabular}

Data are presented as (\%) 
Table 2 Gender identity and self-perceived appearance and desire in the population and sexual minority individual survey

$\begin{array}{cc}\text { Population } & \text { Sexual minority } \\ \text { survey } & \text { individuals survey }\end{array}$

$(\mathrm{n}=1832) \quad(\mathrm{n}=2472)$

MEN

I feel like a man (disagree/totally disagree)

$2.4 \quad .9$

I feel like a women (agree/totally agree)

$1.4 \quad 1.7$

I look masculine (disagree/totally disagree)

$2.2 \quad 2$

I look feminine (agree/totally agree)

1.1

I wish to be more masculine (disagree/totally disagree)

48.8

41.6

I wish to be more feminine (agree/totally agree)

2.3

2.6

\section{WOMEN}

I feel like a man (agree/totally agree)

$\begin{array}{ll}1.7 & 2.8\end{array}$

I feel like a women (disagree/totally disagree)

$\begin{array}{ll}1.5 & 2.8\end{array}$

I look masculine (agree/totally agree)

$1.6 \quad 6.5$

I look feminine (disagree/totally disagree)

1.9

8.1

I wish to be more masculine (agree/totally agree)

1.1

4.1

I wish to be more feminine (disagree/totally disagree)

60.5

43.9

Data are presented as (\%) 
Table 3 Prevalence of gender ambivalent and incongruent identity in the population-survey

\begin{tabular}{lccc}
\hline & Men & Women & Total population \\
& $(\mathrm{n}=894)$ & $(\mathrm{n}=905)$ & $(\mathrm{n}=1799)$ \\
\hline Gender congruent & $97.1(96.0-98.2)$ & $97.5(96.5-98.5)$ & $97.4(96.7-98.1)$ \\
Gender ambivalent & $2.2(1.5-3.4)$ & $1.9(1.0-2.8)$ & $2.0(1.4-2.7)$ \\
Gender incongruent & $0.7(0.2-1.3)$ & $0.6(0.2-1.3)$ & $0.6(0.2-1.0)$ \\
\hline
\end{tabular}

Data are presented as \% (95\% confidence interval). 
Table 4 Self-perceived appearance and desire

\begin{tabular}{lccc}
\hline & Gender & Gender & Gender \\
& ambivalent & incongruent & congruent \\
\hline MEN & $100(\mathrm{n}=20)$ & $100(\mathrm{n}=6)$ & $100(\mathrm{n}=868)$ \\
I look masculine (disagree/totally disagree) & 36.9 & 59.7 & 1.3 \\
I look feminine (agree/totally agree) & 5.8 & 0 & 0.9 \\
I wish to be more masculine (disagree/totally disagree) & 79.2 & 75.5 & 48.6 \\
I wish to be more feminine (agree/totally agree) & 10.6 & 54.0 & 1.8 \\
& & & $100(\mathrm{n}=883)$ \\
WOMEN & $100(\mathrm{n}=17)$ & $100(\mathrm{n}=5)$ & 1.3 \\
I look masculine (agree/totally agree) & 11.9 & 57.3 & 0.9 \\
I look feminine (disagree/totally disagree) & 15.8 & 86.4 & 0.8 \\
I wish to be more masculine (agree/totally agree) & 11.9 & 0 & 60.3 \\
I wish to be more feminine (disagree/totally disagree) & 60.1 & 60.4 & \\
\hline
\end{tabular}

Data are presented as \% within gender ambivalent, gender incongruent or gender congruent sample. 
Table 5 Prevalence of gender ambivalent and incongruent identity in the sexual minority individual survey

\begin{tabular}{lccc}
\hline & Men & Women & Total population \\
& $(\mathrm{n}=1549)$ & $(\mathrm{n}=923)$ & $(\mathrm{n}=2472)$ \\
\hline Gender congruent & $97.3(95.5-98.1)$ & $93.8(92.3-95.4)$ & $96.0(95.2-96.8)$ \\
Gender ambivalent & $1.8(1.1-2.5)$ & $4.1(2.8-5.4)$ & $2.7(2.1-3.3)$ \\
Gender incongruent & $0.9(0.4-1.4)$ & $2.1(1.2-3.0)$ & $1.3(0.9-1.8)$ \\
\hline
\end{tabular}

Data are presented as \% (95\% confidence interval). 
Table 6 Comparison of the prevalence of gender ambivalent and incongruent identity in the population study to the Dutch internet-based survey of Kuyper and Wijsen (2014)

\begin{tabular}{lcccc}
\hline & $\begin{array}{c}\text { Population } \\
\text { survey } \\
(\mathrm{n}=1799)\end{array}$ & $\begin{array}{c}\text { Kuyper and } \\
\text { Wijsen }(2014) \\
(\mathrm{n}=8064)\end{array}$ & $\chi^{2}$ & $p$ \\
\hline Gender ambivalent men & $2.2(1.5-3.4)$ & $4.6(4.0-5.2)$ & 9.97 & .002 \\
Gender ambivalent women & $1.9(1.0-2.8)$ & $3.2(2.7-3.7)$ & 3.90 & .05 \\
Gender incongruent men & $0.7(0.2-1.3)$ & $1.1(0.8-1.4)$ & 0.79 & .37 \\
Gender incongruent women & $0.6(0.2-1.3)$ & $0.8(0.5-1.1)$ & 0.17 & .68 \\
\hline
\end{tabular}

Data are presented as \% (95\% confidence interval).

$\chi^{2}=c$ hi square test 